UDC 544.544:543.655.1

\title{
CONTENT OF ANTHOCYANINS IN THE BARK OF FRUIT AND BERRY PLANTS DUE TO ADAPTION TO LOW TEMPERATURES
}

\author{
(C) I.V. Goncharovska*, V.F. Levon
}

\author{
M.M. Gryshko National Botanical Garden of National Academy of Sciences of \\ Ukraine, Timiryazevska st. 1, Kiev, 01014 (Ukraine), e-mail: Inna_Lera@ukr.net
}

The most important indicator of adaptability cultivar is the winter hardiness of wood. In adverse conditions of autumnwinter period trees of many cultivars may be severely damaged and even die. At the same time, in the process of evolution, a system of adaptive reactions is formed that are associated with a deep change in metabolism and is determined by the speed and depth of its change without violating the consistency between individual functions, so that the unity of the organism and the environment is not violated. This, ultimately, determines the vital activity of the body and its endurance. At this stage of the study, it is shown how plants react to lower temperatures by changing the color of sprouts and accumulating anthocyanins. The aim of the work was to determine the winter hardiness of different cultivars of fruit plants based on physiological processes. Cultivars Malus domestica 'Era' and $M$. domestica 'Vydubytska plakucha' were isolated in the presence of the largest accumulation of secondary metabolites in their generative organs $-378.18-273.33 \mathrm{mg} / 100 \mathrm{~g}$ of dry matter, that is, they are the most plastic before adapting to abiotic factors. The Ribes uva-crispa 'Hamamekii' and Viburnum opulus genotypes with the lowest overall quantity of anthocyanins were $75.79-67.37 \mathrm{mg} / 100 \mathrm{~g}$ of dry matter. Based on the results of the analysis found that the highest content of anthocyanins in the cultivar Everest, and the lowest - cultivar John.

Keywords: malus, crabapple, fruit and berry plants, anthocyanins, adaptation, winter hardiness.

Abbreviations: ROS - reactive oxygen species; NBG - National Botanical garden.

\section{Introduction}

Anthocyanins are natural colorants of plants from the flavonoid group. The formation of anthocyanins is favored by low temperature and intense lighting, but their full biological functions have not yet been clarified [1]. Anthocyanins give color to the petals of the flowers, thereby attracting pollinating insects [2]. All anthocyanins contain positively charged oxygen (oxonium) in the heterocyclic fragment. In plant tissues, anthocyanins are usually found in the form of glycosides of polyhydroxy and polymethoxy derivatives of 2-phenylbenzopyryllium or flavyllium ions [3].

Anthocyanins are synthesized from their aglycones of anthocyanidins after the merger with glycosyl and methyl groups in various combinations. The resulting structural diversity of anthocyanins is one of the factors influencing the color diversity of flowers, fruits, etc. [4, 5].

Schaefer and Rolshausen (2006), formulated the "protective indication hypothesis", they believe that anthocyanins developed in response to abiotic stressors such as bright light, drought, sub-zero temperatures, because anthocyanins have the same phenylpropanoid-biosynthetic pathway with many protective phenolic compounds. Anthocyanins are usually formed in the vegetative and generative organs of plants under stress, such as high light, UV radiation, low temperatures, drought, and nutrient deficiencies of nitrogen and phosphorus, bacterial and fungal infections, injuries, herbicides, and various pollutants $[6-8,9,10,11]$. Therefore, it is proved that eco-factors such as temperature, light, water, and wood damage lead to the stimulation of anthocyanin biosynthesis.

There are several different ways that anthocyanins can help plants protect themselves. These include both direct roles of chemical repellents and more indirect roles as visual cues. Like other flavonoids, anthocyanins have

Goncharovska Inna Valerievna - Researcher, e-mail: Inna_Lera@ukr.net

Levon Vladimir Fedorovych - Senior Researcher, e-mail: vflevon@gmail.com pronounced antiviral, antibacterial, and fungicidal activity $[12,13]$.

Anthocyanins of flowers play an important role in pollination of plants, attracting pollinating insects

${ }^{*}$ Corresponding author. 
(bees, bumblebees). Apple petals, for example, are white inside, but have a soft pink ("anthocyanin") hue on the outside, which attracts bees [14].

The functions of anthocyanins in leaves, sprouts, roots, and other parts of plants have long attracted the attention of scientists. The main functional hypotheses include: protection of mitochondria from the adverse effects of excess light, attenuation of ultraviolet radiation, and antioxidant activity. However, recent data indicate that to a certain extent, each of these processes, which are affected by anthocyanins, are very different in different plant species. We suggest that anthocyanins may have a more indirect role as modulators of signaling oxygen cascades that are involved in plant growth and development, responses to stress, and gene expression.

Anthocyanins can directly absorb reactive oxygen species (ROS) they are usually colorless or light blue in the $\mathrm{pH}$ of the cytoplasm, but they change their color to red after being transported to the vacuole. Regarding the role of ROS in plants, there is an argument for the functions of anthocyanins in vegetative organs that it is a modulator of signal transmission cascades at the level of physiological responses to stress. There is increasing empirical evidence to suggest that ROS can perform many useful functions in plants. Indeed, ROS appears to be actively produced by plant cells and is used as signaling molecules in such diverse processes as growth and development, stomatal closure, protection from pathogens, and abiotic stress responses [15]. In plant cells, chloroplasts and mitochondria are the main sources of ROS, which are generated by aerobic reactions that are involved in photosynthesis and respiration [16, 17]. ROS are also produced in the peroxisome during photo-respiration and fatty acid oxidation [18].

Mittler (2002) argued that the amount of ROS can be used by plants as an indicator of intracellular stress. Excess ROS potentially causes cellular damage to phospholipid membranes, proteins, and nucleic acids, and this is traditionally considered harmful to the functioning of plants [19]. When ROS levels rise in response to abiotic stress, plants face the challenge of removing excess ROS to avoid programmed cell death, while keeping levels of various types of ROS low enough for signaling purposes.

Both $\mathrm{ROS}$ and $\mathrm{O}_{3}$ have an effect on plants, causing massive changes in transcription, translation, and metabolism, resulting in a reduction in plant productivity of up to $15 \%$ [20]. In addition, it is known that the content of numerous free radicals in plants increases after exposure to $\mathrm{O}_{3}$ [21]. These radicals can destroy various organelles, causing programmed cell death and reducing the yield of various crops [22]. However, on the other hand, ROS can protect plants from the harmful effects of ozone.

Carbon dioxide has a similar effect on the plant body, although $\mathrm{CO}_{2}$ is important for photosynthesis, but increased levels of $\mathrm{CO}_{2}$ can have a negative effect on plants. Research by Loladze (2002), based on more than 130 plant species, has shown that increased $\mathrm{CO}_{2}$ levels can reduce the mineral content by an average of $8 \%$ and increase the ratio of soluble carbohydrates to proteins.

Biochemical studies of the content of biologically active substances in the bark of fruit and berry plants in the forest-Steppe of Ukraine were conducted for the first time.

Secondary metabolites in plants are divided into three main groups: alkaloids, terpenoids, and phenylpropanoids [23].

The end products of the flavonoid pathway are anthocyanins, which are formed as a result of condensation of anthocyanidins and sugars. There are six main anthocyanidins identified in plant organs: delphinidin (D), cyanidin $(\mathrm{C})$, peonidin $(\mathrm{Pn})$, petunidin $(\mathrm{Pt})$, malvidin $(\mathrm{M})$, and pelargonidin $(\mathrm{Pg})$. many anthocyanins can be obtained by glycosing at the 3 C-ring position and acylating these sugars [24-25].

\section{Material and methods}

Plant material. The objects of the study were non-traditional fruit plants from the collection of the Department of acclimatization of fruit plants of the National botanical garden (NBG) M. M. Grishko NAS of Ukraine in 2016 to representatives of plants in crabapple, namely: John, Royal Red, Royalty, Everest, Niedzwetzkyana, Ola, Rozeva, Professor Shprengler, in 2017 to representatives of the genus M. domestica: Vydubetska plakucha (V.p.), V.p. $\times$ Renet Symyrenko, V.p. $\times$ Starkrimson, V.p. $\times$ Malus baccata, V.p. $\times$ Renet Koksa Oranzhevyi, V.p. $\times$ Uralske nalyvne, V.p. $\times$ Slava peremozhcyam, V.p. $\times$ Oranzheve, V.p. $\times$ Antor, in 2019 to representatives of plants of other families: Ribes uva-crispa 'Hamamekii' - grafted on the stem, Malus domestica 'Era' - decorative crabapple and Malus domestica 'Vydubytska plakucha' - apple tree with a weeping crown shape, Malus baccata 'Pendula'- decorative apple tree, Amygdalus triloba, Morus alba 'Pendula', Elaeagnus multiflora, Viburnum opulus, Cornus mas 'Vydubetsky' and Cornus mas 'Svitlyachok' - of our selection. 
In the second half of the twentieth century, scientists of the NBG on the territory of the Vydubetskyi Mikhailovskyi Monastery, which is located near the NBG, found a cultivar of apple trees, which was called 'Vydubetska plakucha'.

The 'Vydubetska plakucha' was involved in the breeding process due to the high winter hardiness and peculiarities of the habit of the crown, which has a weeping shape, to study the inheritance of 'weeping' when crossed with cultivars and to select forms for decorative gardening.

Crabapple are small-fruited apple trees of American origin, which are widely used for decorative gardening.

Their origin is associated with the Siberian berry apple tree and Chinese plum-leafed pollinated cultivars. Most of them were obtained from sowing seeds exported from Russia, the smaller - from subsequent crosses with local cultivars.

Ornamental crabapple are not common in Ukraine and are not well understood. Studies on the content of anthocyanins were conducted in connection with the sharp fluctuations in temperatures during the winter dormancy of plants.

The course of the analysis. The quantity of anthocyanins was determined using a spectrophotometric method at a wavelength of $530 \mathrm{~nm}$, using alcohol extraction from a homogenate of plant raw materials acidified with $3.5 \%$ hydrochloric acid [26].

The measurements were carried out on a Zalimp KF 77 photoelectrocolorimeter (Poland).

Calculations of the content of anthocyanins (in terms of cyanidin-3-glucoside) were made using the formula:

$$
C_{a \mu}=\frac{D \cdot V \cdot R \cdot K}{l \cdot m}
$$

where, D - the optical density of the solution; V - the volume of the extract, $\mathrm{ml}$; $\mathrm{R}$ - dilution ratio of a solution of $3.5 \%$ hydrochloric acid; 1 - a pathlength of the cuvette, $\mathrm{cm} ; \mathrm{m}$ - weighed quantity, $\mathrm{g} ; \mathrm{K}$ - is the conversion factor.

The number of parallel determinations was 3. The accuracy of the method was in the range of $2.5-4.8 \%$.

The data obtained were presented as $\mathrm{mg} / 100 \mathrm{~g}$ of dry matter in terms of cyanidin glycosides. Statistically processed data is shown on histograms as arithmetic means and their standard errors. The significance level was set at $\alpha=0.05$. The statistical analysis was performed with IBM SPSS Statistics, release 23.0.

\section{Results}

For the study representatives of 9 - cultivars apple tree, 8 - crabapple and 10 non-traditional fruit plants of different genetic origin were selected from the collection of Acclimatization of Fruit Plants Department M.M. Gryshko NBG of National Academy of Sciences of Ukraine, in order to confirm or refute the visual assessment of frost and winter hardiness of fruit and berry crops by the content of anthocyanins, that is, their accumulation during stress during sharp temperature fluctuations.

NBG is located on the South-Eastern outskirts of Kiev on the Pechersk slopes of the low Kiev hills in the Zverinets tract. The main type of soil on the territory of the NBG is dark gray podzol, which lies on loess and forestbearing rocks and brown clays (the amount of humus is $0.5-2.0 \%$ ). The duration of the frost-free period over the years of the study averaged 184 days.

Biochemical studies of the content of biologically active substances in Crabapple and apple hybrids 'Vydubytska plakucha' in the Forest-Steppe of Ukraine was carried out for the first time.

In 2016, the content of anthocyanins was determined in the aerial organs of representatives of the genus Malus, namely in crabapple, the name of which is mentioned in the section of methods and materials. Based on the results of the analysis, it was found that the highest content of anthocyanins in cultivar Everest $-587.5 \mathrm{mg} / 100 \mathrm{~g}$, and the lowest in cultivar John $-41.24 \mathrm{mg} / 100 \mathrm{~g}$ of dry matter (Fig. 1).

In 2017, the content of anthocyanins in the sprouts of decorative forms of representatives of the genus Malus was determined. It was found that the highest content of the aforementioned biologically active compounds has the apple-tree cultivar 'Vydubetska plakucha'. The content of anthocyanins reaches the level of $218 \mathrm{mg} / 100 \mathrm{~g}$ of dry matter, also a rather high content of anthocyanins in the hybrid V. p. $\times$ Renet Koksa Oranzhevyi $-208 \mathrm{mg} / 100 \mathrm{~g}$ of dry matter (Fig. 2). 


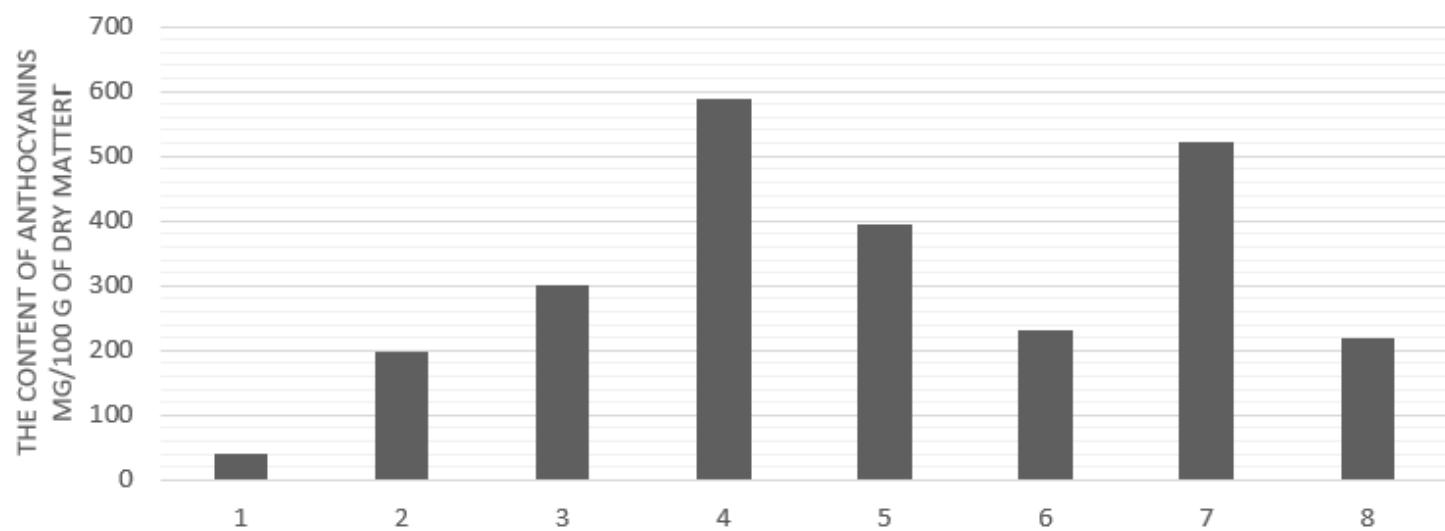

Fig. 1. The content of anthocyanins in sprouts of cultivars and hybrids of decorative forms of representatives of the genus Malus during the winter calm: John, Royal Red, Royalty, Everest, Niedzwetzkyana, Ola, Rozeva, Professor Shprengler

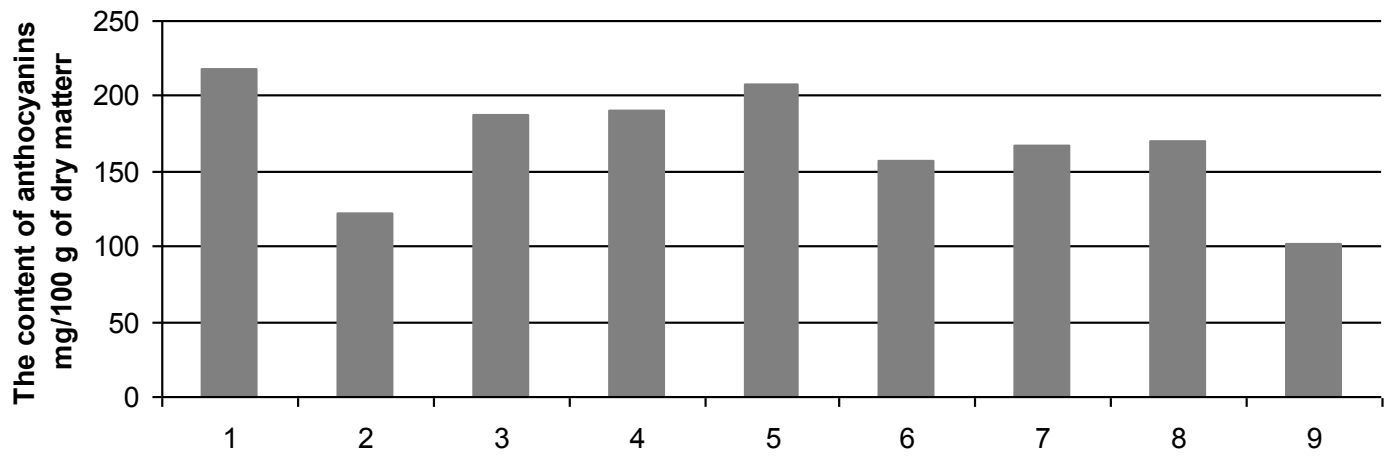

Fig. 2. The content of anthocyanins in sprouts of cultivars and hybrids of decorative forms of representatives of the genus Malus during the winter calm: 1 - Vydubetska plakucha, 2 -Vydubetska plakucha $\times$ Renet Symyrenko 3 - V. p. $\times$ Starkrimson, 4 - V. p. $\times$ Malus baccata, $5-$ V. p. $\times$ Renet Koksa Oranzevyi, $6-$ V. p.

$\times$ Uralske nalyvne, $7-$ V.p. $\times$ Slava peremozhcyam, $8-$ V.p. $\times$ Oranzeve, $9-$ V. p. $\times$ Antor

Literature data indicate that the purple color of the sprouts is due to anthocyanins. Our studies have shown that the apple-tree cultivar 'Vydubetska plakucha', the type of apple-tree Niedzwetzkyana, and the Everest ridge have the highest content of anthocyanins, although the sprouts of the apple-tree cultivar 'Vydubetska plakucha' are brown with an orange tint, and the sprouts of the Everest ridge are bright orange, therefore, judge the content of anthocyanins only by color sprouts are not always correct and a large accumulation of anthocyanins in sprouts indicates the intentional protection of plants from adverse environmental factors. In connection with these data, the investigation was also extended with other non-traditional fruit plants.

In 2019 thus, the content of anthocyanins in the bark of fruit and berry crops was determined in connection with the adaptation of plants to fluctuations in low temperatures. The fluctuation of temperature was observed from $-14{ }^{\circ} \mathrm{C}$ to $+10{ }^{\circ} \mathrm{C}$ (Fig. 3).

According to visual observations after overwintering of fruit and berry plants, the degree of their freezing was determined. The highest percentage of frozen growth of annual sprouts was observed in plants Morus alba 'Pendula' and Viburnum opulus, visual observations were confirmed by laboratory, because their bark showed the lowest content of anthocyanins $-55.38-67.37 \mathrm{mg} / \mathrm{g}$ of dry matter, respectively.

The highest anthocyanin content was found in the bark of the Apple tree genotypes M. domestica 'Era' and M. domestica 'Vydubytska plakucha', 378 and $273 \mathrm{mg} / 100 \mathrm{~g}$ of dry matter, respectively (Fig. 4).

It was found that the change in the quantity of anthocyanins in the bark of fruit and berry plants reacts even to small fluctuations in temperature, an inversely proportional relationship is observed: a decrease in the average 
daily temperature towards negative marks leads to an increase in the number of anthocyanins with some delay in time (3-5 days). An increase in the average daily temperature leads to a decrease in the number of anthocyanins.

Comparing the dynamics of anthocyanin content in the cortex of research objects in the winter period, we observe fluctuations in the content of biologically active substances due to an increase and decrease in temperature. The maximum accumulation of anthocyanins in the variety M. domestica 'Era', the minimum in Morus alba 'Pendula' (Fig. 5).

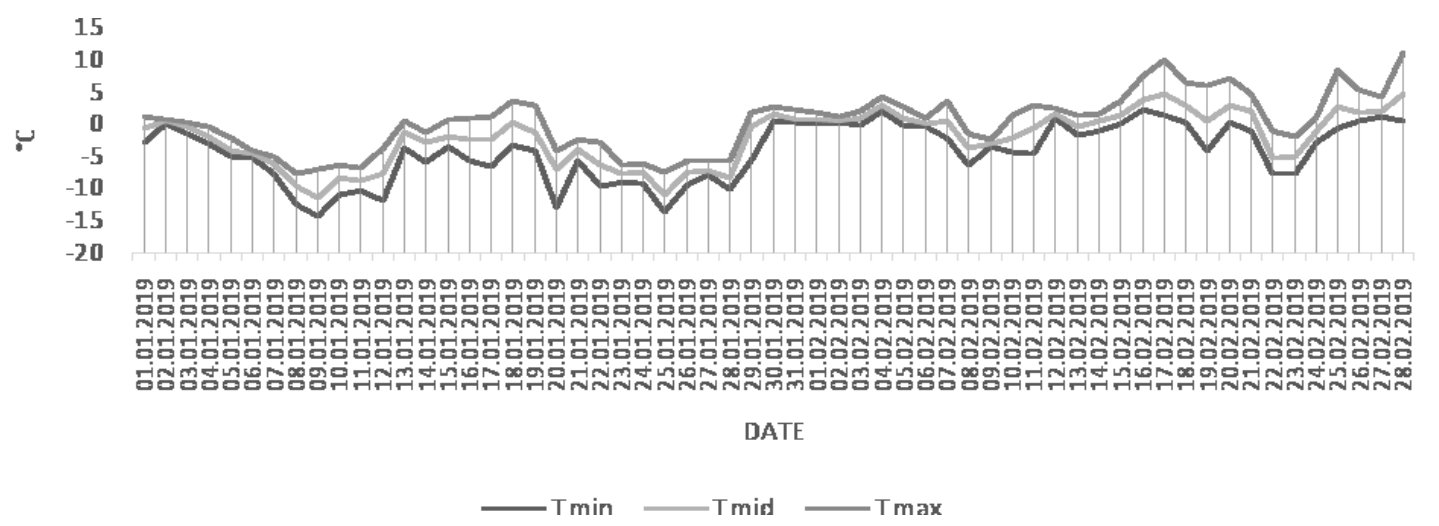

Fig. 3. The minimum, average, maximum temperature in January-February 2019

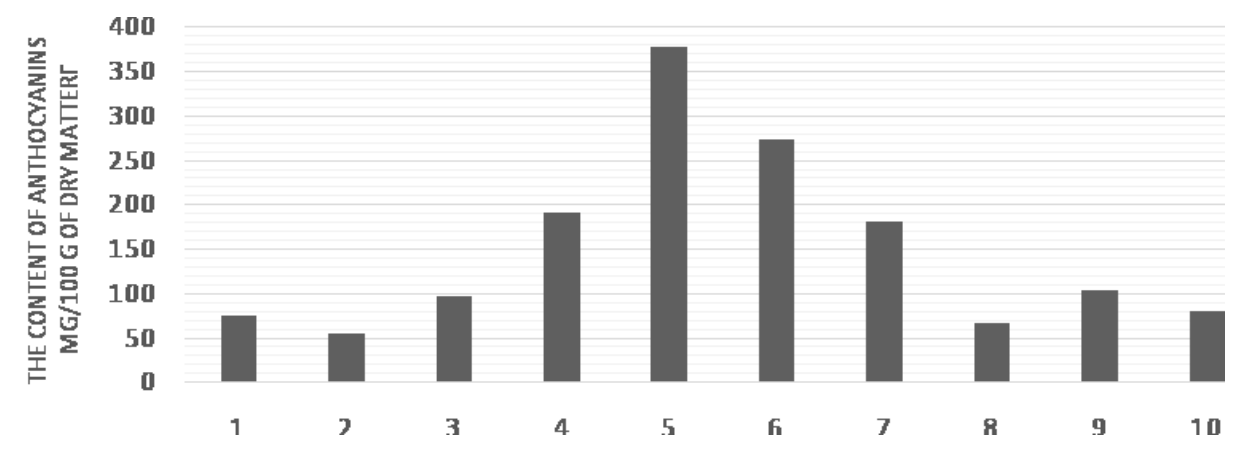

Fig. 4. The content of anthocyanins in the cortex of fruit plants during winter dormancy:1 - Ribes uva-crispa 'Hamamekii', 2 - Morus alba 'Pendula', 3 - Elaeagnus multiflora, 4 - Malus baccata 'Pendula', 5 - Malus domestica 'Era', 6 - Malus domestica 'Vydubytska plakucha', 7 - Amygdalus triloba, 8 - Viburnum opulus, 9 Cornus mas 'Vydubetskyi', 10 - Cornus mas 'Svitlyachok'

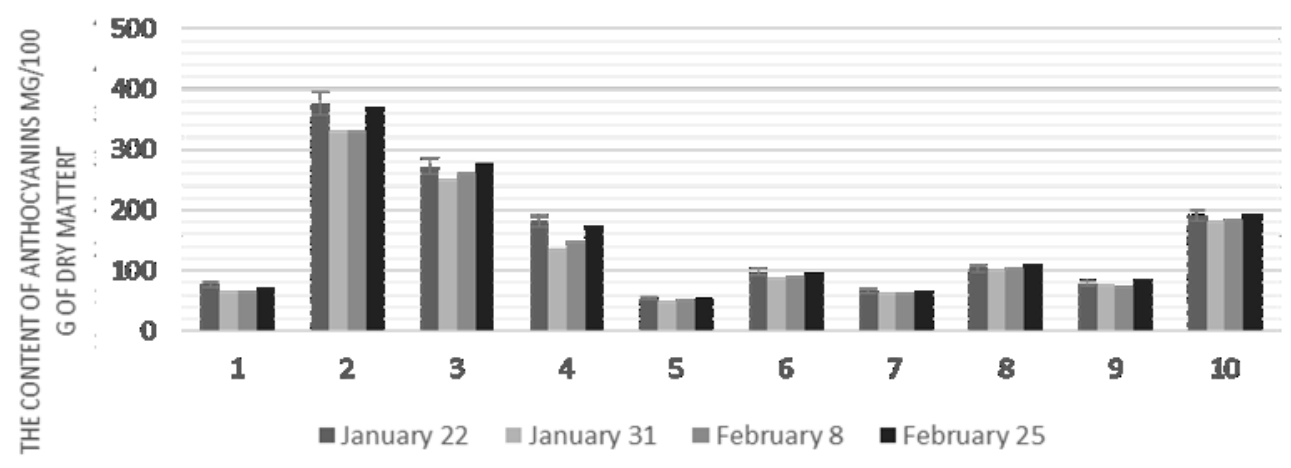

Fig. 5. Comparison of the dynamics of anthocyanin content in the bark of fruit and berry plants during the winter dormancy: 1 - Ribes uva-crispa 'Hamamekii', 2 - Malus domestica 'Era', 3 - Malus domestica 'Vydubytska plakucha', 4 - Amygdalus triloba, 5-Morus alba 'Pendula', 6 - Elaeagnus multiflora, 7 Viburnum opulus, 8 - 'Cornus mas 'Vydubetskyi', 9 - Cornus mas 'Svitlyachok', 10 - Malus baccata 'Pendula' 


\section{Discussion}

Different plant genotypes have unequal resistance to winter hardiness components. However, according to Krivintsov [14], winter hardiness of fruit plant cultivars is determined not only by their frost resistance and these signs should not be contrasted with one another. Therefore, winter hardiness of fruit plants is a complex property and consists of many specific signs (components) of resistance to various types of frost exposure during the wintering period.

Water management also plays a role in determining plant sustainability. For example, trees from non-irrigated apple trees may be more unstable than apple trees with good irrigation [19]. Water saturation in the summer is used throughout the world as an indicator of sustainability and to assess the general condition of the genotype.

All areas where research objects grow have enough irrigation, so our studies are objective and reliable.

\section{Conclusions}

It is known that the development of cold and frost resistance of plants, as well as adaptation to high temperatures, includes an increase in the activity of antioxidant enzymes. The accumulation of ROS at low temperatures can be an inducer of activation of the enzymatic system of antioxidant protection. The effect on plants of both high and low temperatures causes them to synthesize stress proteins-heat shock and cold shock proteins. Apparently, ROS can be attributed to important mediators of the temperature signal transmission that initiates changes in the protein spectrum. A moderate increase in ROS generation can lead to activation of classical defense mechanisms (synthesis of antioxidant enzymes, stress proteins, etc.). a stronger ROS signal can induce programmed cell death. Finally, uncontrolled ROS formation leads to deep damage to biomacromolecules, membranes, and tissue necrosis [12].

We suggest that anthocyanins provide various mechanisms for modulating warning signals that mitigate the effects of abiotic and biotic factors. As explained below, this role is achieved in three interrelated ways: by protecting antioxidant enzymes, by directly removing ROS, and by interacting with other molecules in the signal pathways.

Summing up the study of the anthocyanin content, we found that the highest content of anthocyanins from the 17 presented plant genotypes in Apple trees is $M$. purpurea Everest, $M$. domestica 'Era' and 'Vydubytska plakucha', that is, they are the most resistant and plastic to low temperatures, the lowest in plants Morus alba 'Pendula' and Viburnum opulus.

It is believed that Viburnum opulus is not demanding to extreme weather conditions and easily tolerates drought and frost, but nevertheless, in the Northern Forest-Steppe of Ukraine, it is damaged by low temperatures.

It is important that visual observations were confirmed by laboratory that is, determining the content of secondary metabolites, namely anthocyanins in the bark of annual sprouts in the winter, can be considered one of the markers for determining the winter and frost resistance of plants. By this way, the identified genotypes could be used as parents in breeding studies to develop new varieties tolerant to cold weather conditions.

\section{References}

1. Korovin F.I. Rasteniya i ekstremal'nyye temperatury. [Plants and extreme temperatures]. Leningrad, 1984, 271 p. (in Russ.).

2. Loladze I. Trends in Ecology \& Evolution, 2002, vol. 17, pp. 457-461. DOI: 10.1016/S0169-5347(02)02587-9.

3. Brouillard R. Anthocyanins as food colors, New York: Academic Press, 1982, vol. 1, pp. 1-40.

4. Mazza G. Anthocyanins in fruits, vegetables and grains, CRC Press Inc, 1993, 362 p.

5. Castellarin S., Bavaresco L., Falginella L., Gonçalves M., Di Gaspero G. The biochemistry of the grape berry, Sharja: Bentham Science Publishers, 2012, pp. 89-110.

6. Dixon R.A., Harrison M.J., Paiva N.L. Physiologia Plantarum, 1995, vol. 93(2), pp. 385-392. DOI: 10.1111/j.13993054.1995.tb02243.x

7. Fiscus E.L., Booker F.L., Burkey K.O. Plant Cell. Environ., 1996, vol. 28, pp. 997-1011.

8. Noctor G., Veljovic-Jovanovic S., Driscoll S., Novitskaya L., Foyer C.H. Annals of Botany, 2002, vol. 89, pp. 841850.

9. Konczak I., Zhang W. Journal of Biomedicine and Biotechnology, 2004, vol. 5, pp. 239-240.

10. Wrolstad R.E. J. Food. Sci., 2004, vol. 69(5), pp. 419-425.

11. Karabanov I.A. Flavonoidy v mire rasteniy. [Flavonoids in the plant world]. Minsk, 1981, 80 p. (in Russ.).

12. Mittler R. Trends in Plant Science, 2002, vol. 7, pp. 405-410.

13. Rhoads D.M., Umbach A.L., Subbaiah C.C., Siedow J.N. Plant Physiology, 2006, vol. 141, pp. 357-366.

14. Alscher R.G., Donahue J.L., Cramer C.L. Physiol. Plant., 1997, vol. 100, pp. 224-233.

15. Wrolstad R.E. J. Food. Sci., 2004, vol. 69(5), pp. 419-425. 
16. Kabera J.N., Semana E., Mussa A.R., He X. Journal of Pharmacy and Pharmacology, 2014, vol. 2, pp. $377-392$.

17. Terrier N., Ollé D., Verriès C., Cheynier V. Grapevine molecular physiology \& biotechnology, Dordrecht: Springer, 2009, pp. 365-388.

18. Di Ferdinando M., Brunetti C., Fini A., Tattini M. Abiotic stress responses in plants: metabolism, productivity and sustainability. New York: Springer Science \& Business Media, 2012, pp. 159-179.

19. Harborne J.B. Comparative photochemistry, Academic Press, London, 1996, pp. 271-295.

20. Kolupaev Yu.E., Karpec Yu.V. Fiziologiya i biokhimiya kul'turnykh rasteniy, 2009, Vol. 41(2), pp. 95-108. (in Russ.).

21. Wilkinson S., Mills G., Illidge R., Davies W.J. J. Exp. Bot., 2012, vol. 63, pp. 527-536.

22. Pourcel L., Routaboul J.M., Cheynier V., Lepiniec L., Debeaujon I. Trends in Plant Science, 2007, vol. 12, pp. 29-36.

23. Schaefer H.M., Rolshausen G. Bio. Essays., 2006, vol. 28, pp. 65-71. DOI: 10.1002/bies.20340.

24. Terrier N., Ollé D., Verriès C., Cheynier V. Grapevine molecular physiology \& biotechnology, Dordrecht: Springer, 2009, pp. 365-388.

25. Fiscus E.L., Booker F.L., Burkey K.O. Plant Cell. Environ., 1996, vol. 28, pp. 997-1011.

26. Kriventsov V.I. Metodicheskiye rekomendatsii po analizu plodov na biokhimicheskiy sostav. [Methodical recommendations for the analysis of fruits for biochemical composition]. Yalta, 1982, 21 p. (in Russ.).

Received May 7, 2020

Revised January 12, 2021

Accepted January 13, 2021

For citing: Goncharovska I.V., Levon V.F. Khimiya Rastitel'nogo Syr'ya, 2021, no. 1, pp. 233-239. (in Russ.). DOI: 10.14258 jcprm.2021017747. 
